\title{
Effect of top cover material on productivity of solar distillation unit
}

\author{
Hosney Ara Begum ${ }^{1}$, M. Abu Yousuf, K Siddique-e Rabbani \\ Department of Biomedical Physics \& Technology, Dhaka University, Dhaka, \\ ${ }^{1}$ Presently at: Industrial Physics Division, BCSIR Laboratories Dhaka, \\ hosneyara@gmail.com, aybabu@gmail.com, rabbani@du.ac.bd
}

\begin{abstract}
This work was taken up to design a cost effective and simple domestic scale solar water distillation device for use in the coastal villages of Bangladesh where saline free drinking water is scarce. This study mainly looked at the feasibility of using stretched transparent PVC cover in solar distillation devices in lieu of traditionally used transparent glass sheet. To increase total evaporative surface area of the bottom of stills, those were covered with black cotton fabrics with extended fibers. For the same angle of inclination $\left(13^{0}\right)$ of the transparent cover, the average amount of distilled water produced by the transparent PVC sheet covered still was about $42 \%$ of that collected from a glass sheet covered still. The reason behind this poor performance could be traced to the increased surface adhesion of condensed water droplets with the PVC cover, which essentially scattered sunrays away from the solar still. So the way to go is to find a suitable plastic sheet material that has reduced surface adhesion to water or to find a coating material that can reduce surface adhesion too. Unless this can be done, traditional glass covered solar distillation device still remains the cover material of choice.
\end{abstract}

Key words: Solar distillation, safe drinking water, desalination, transparent cover for solar stills, basin type solar still.

\section{INTRODUCTION}

Provision of safe drinking water for all still remains a global challenge in spite of astounding developments in science \& technology. Safe drinking water is the most important ingredient for sustaining life on the earth. Though water is abundant, only a tiny fraction of the total amount can be used for drinking purposes. In the coastal region of Bangladesh, brackish or saline water prevails everywhere and people are always in search of safe drinking water. Even water of freshwater ponds have turned saline in many places. During natural disasters like flood or in emergencies, safe drinking water is the commodity that is in dire need first. Again in various places, whether in the hilly areas or in the plain lands, indigenous sources of water have mostly become contaminated by heavy metals or by chemical wastes. Saline contamination of groundwater in coastal area of Bangladesh has reached alarming conditions since mid-80s due to rise of sea level, uncontrolled shrimp cultivation, climate change and other reasons. As a result, millions of people in the coastal regions of Bangladesh find themselves confronting a big hurdle due to the overwhelming presence of saline or unsafe drinking water [Bendfeld et al 1998, Islam et al 2013].

Solar energy can be used effectively to purify saline water efficiently [Gupta 2013]. According to geographical position, Bangladesh is a tropical country, lying within latitudes $23.68^{\circ} \mathrm{N}$ and $23.94^{\circ} \mathrm{N}$, and has a good amount of sunshine all the year round [Sadrul 2001]. One can use solar energy for distillation of saline or brackish water for the fulfillment of demand of safe drinking water in especially coastal and rural areas [Khan et al 2008, Rahman et al 2001, Rahman et al 1997]. 
Since majority of people live in isolated villages in Bangladesh at great distances from each other, piped water facilities as in the cities are not practical. Therefore, technology for domestic scale solution is needed, which has to be affordable and simple to use. The aim is to come up with a low cost and practical design of a solar distillation unit that can provide sufficient amount of safe drinking water for a family with five members. An experimental investigation on such a design was carried out in the Department of Biomedical Physics and Technology, Dhaka University. Basin type desalination units with transparent glass cover is typically used by most traditional designs of solar distillation units. However, it is brittle and can break easily, and is heavy and expensive. Therefore, we sought alternative materials to replace glass, and in the present work, transparent PVC sheet was tried and its performance compared to a glass cover was studied, keeping all other parameters the same.

\section{MATERIALS AND METHODS}

In the present work two solar powered small sized desalination units or 'solar stills' were designed and fabricated using locally available low cost materials. However, one had a transparent PVC film as the cover while the other had a transparent glass cover. Technology used to construct the stills was purely indigenous. It has an inclined cover on one side only, facing south, as shown in Figure 1. The transparent covers of both the basic devices under study had an inclination of $13^{\circ}$.
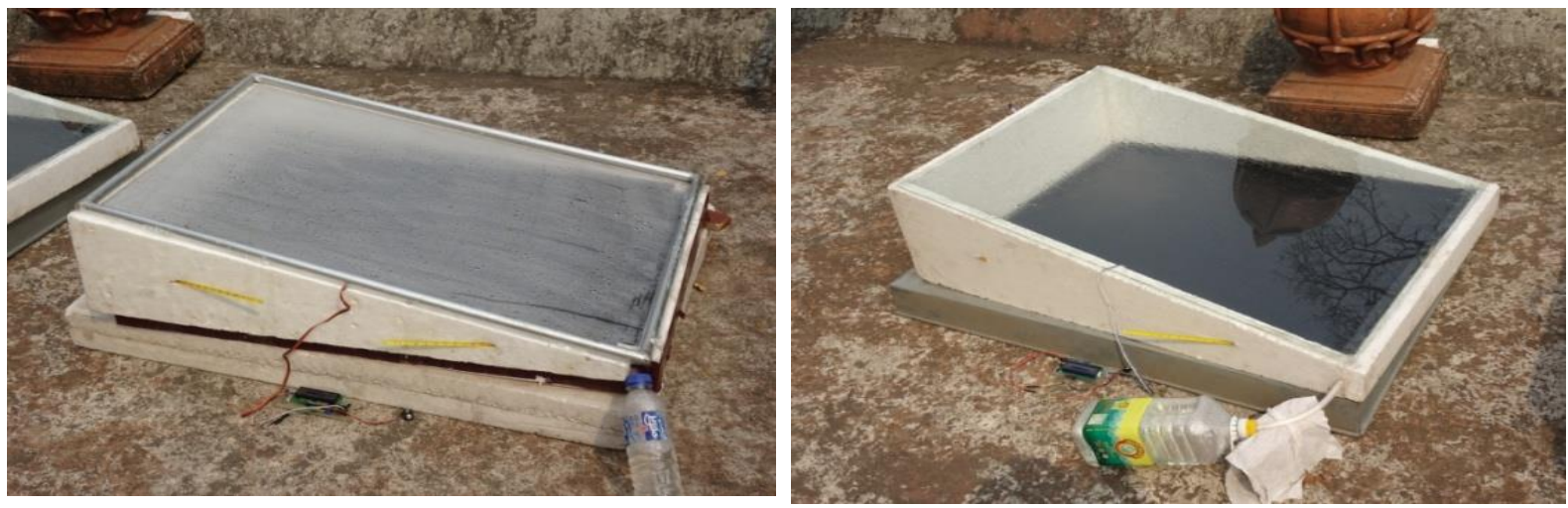

Figure 1: Basin type solar still with transparent PVC sheet cover (left) and glass sheet cover (right).

In designing these solar desalination units, the main considerations were availability of materials, cost, efficiency, ease of construction and ease of maintenance. A schematic is shown in Figure 2. The base and side walls of the basin were constructed using 1.5 inch thick polystyrene foam slabs. The vertical and horizontal sections were attached appropriately to each other using glue and the joints were strengthened using inserted toothpicks. The inside of the base was covered with a self-adhesive black PVC sheet. A thick black cotton towel with elongated fibers was fixed on this PVC sheet. The idea of using a towel, which was novel, was to maximize surface area for water evaporation. The towel would be kept soaked with water to be distilled taking care that the cotton fibres of the towel are above the water surface. This will increase the effective surface area compared to a simple pool of water which is used traditionally. The device had separate water inlet port, washout port and distilled water collection port. A provision was made to ensure a continuous supply of water to be treated. For this a jar of water was placed at a slightly raised level and it was connected to the basin of the solar still through a hospital saline tube.

One of the two solar stills had a cover made of about $200 \mu \mathrm{m}$ thick transparent PVC sheet, tightly stretched and affixed within a rectangular frame made of aluminium pipes. The other was simply a $3 \mathrm{~mm}$ thick 
transparent glass sheet. Both covers were attached to the respective devices using suitable mechanical fixtures. Silicon sealant was used to make the joints air tight. The devices were placed on a raised level so that the distillate collection bottles can be placed at a slightly lower level as shown in Figure 1. Probes of a multichannel digital thermometer were inserted and fixed at three positions inside both the stills, near the water inlet, near the water outlet and at the middle. The probes of two digital hygrometers were also inserted inside the stills and fixed near the middle.

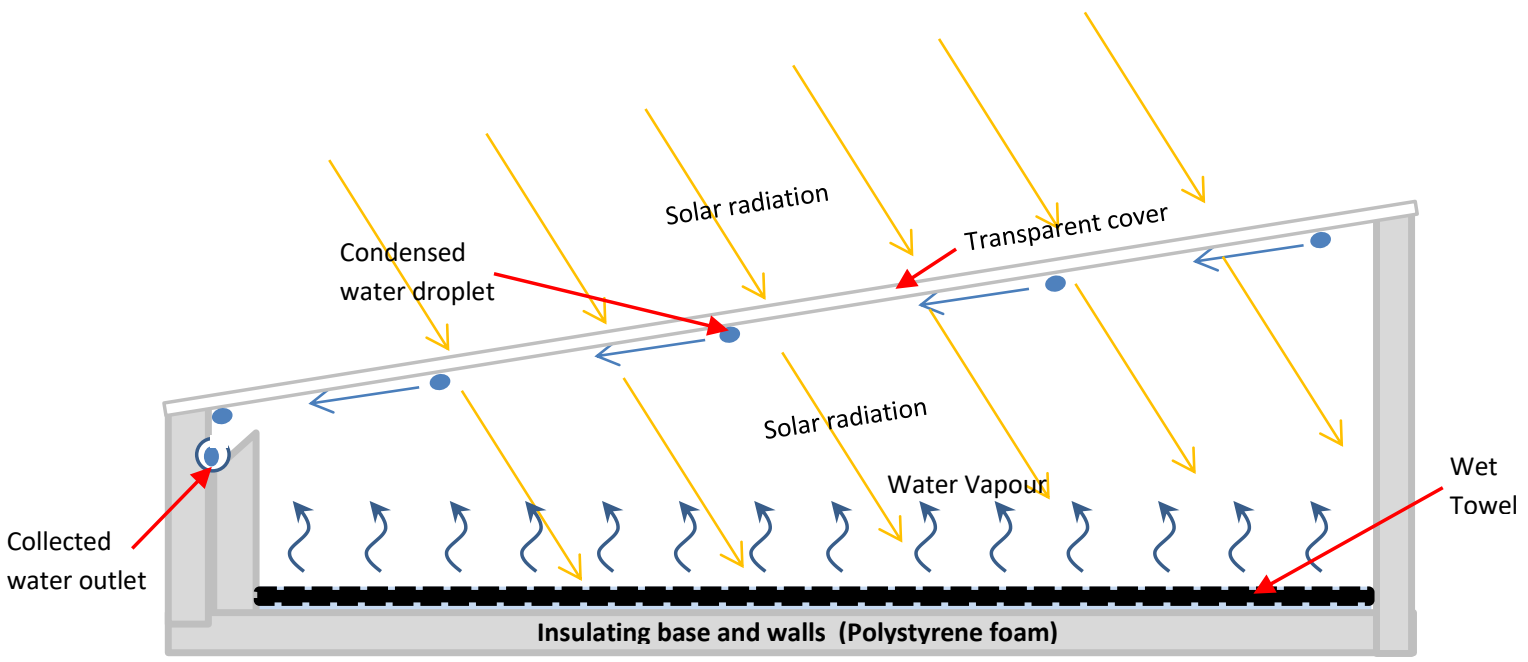

Fig. 2: A schematic of the basic solar still.

As indicated in Figure 2, the solar still is heated through 'Green House Effect'. Light in the visible and short infra-red range from the sun enters the still through the transparent top cover which is absorbed by the wet black towel, and its temperature increases. This hot towel in turn radiates heat energy in the form of infra-red rays with long wavelength for which the glass cover is almost opaque. Thus heat energy becomes trapped inside and keeps on accumulating with time, increasing the temperature inside. The temperature reaches a maximum when the heat gained from solar energy just equals the heat lost by the device to the surroundings. This also causes evaporation of water inside and the water vapour moves upwards. The top cover is continually cooled by the air outside and so has a lower temperature than the humid air within. This causes condensation of water vapour underneath the transparent cover and the air, which is dryer and cooler, comes down, to be heated again and to get water vapour from the hot wet towel. Thus a circulation of air builds up which continually transfers moisture from the wet towel to the underneath of the transparent cover. When the condensed drops are sufficiently large so that their weight due to gravity can overcome the surface adhesion forces with the cover material, the water drops trickle down the inner inclined surface of the top cover and eventually collects in an open drainpipe place at the bottom, through which water is brought outside the still and collected in a storage vessel.

The comparative experiments to study the effects of the top cover was performed on several days in the month of March when there is usually no cloud cover in Bangladesh except some aerial haze due to dust particles occasionally. At the beginning two litres of water was poured into the basin of each solar still. This amount was adequate to keep the towels just soaked. The fibres of the towel remain moist due to capillary action. To provide a continuous supply of water as it evaporates, a jar of water was placed at a slightly raised level and was connected to the basin through a hospital saline set with controlled entry of 
water. The procedure was initiated at 10:00am in the morning for both the devices and the distilled water was collected at 3:00pm in the afternoon, giving a total measurement period of 5 hours. The maximum ambient temperature of the day was recorded. Both the devices were operated simultaneously so that all weather and environmental conditions remain the same. Similar study was carried out on three days to arrive at an average. The temperature inside the stills at different points (near water inlet, near middle, near water outlet) and at different times of the day were recorded and were plotted to give an understanding of the thermal behaviour of the two devices. The ambient temperatures were also recorded simultaneously. The relative humidity inside the two devices at different times of the day were also recorded and plotted.

The cover area for the devices was about $0.5 \mathrm{~m}^{2}$. After the measurements, the amount of collected distillate was normalized to that for $1 \mathrm{~m}^{2}$ of area for easy comparison with work to be carried out later.

\section{RESULTS AND OBSERVATIONS}

Temperature profiles inside the solar still at water inlet side (higher part of the chamber), at the middle part and at the water outlet side (lower part of the chamber) together with that of ambient (outside) are shown in Figure 3. These distributions are important from point of view of the dynamics of the thermal condition
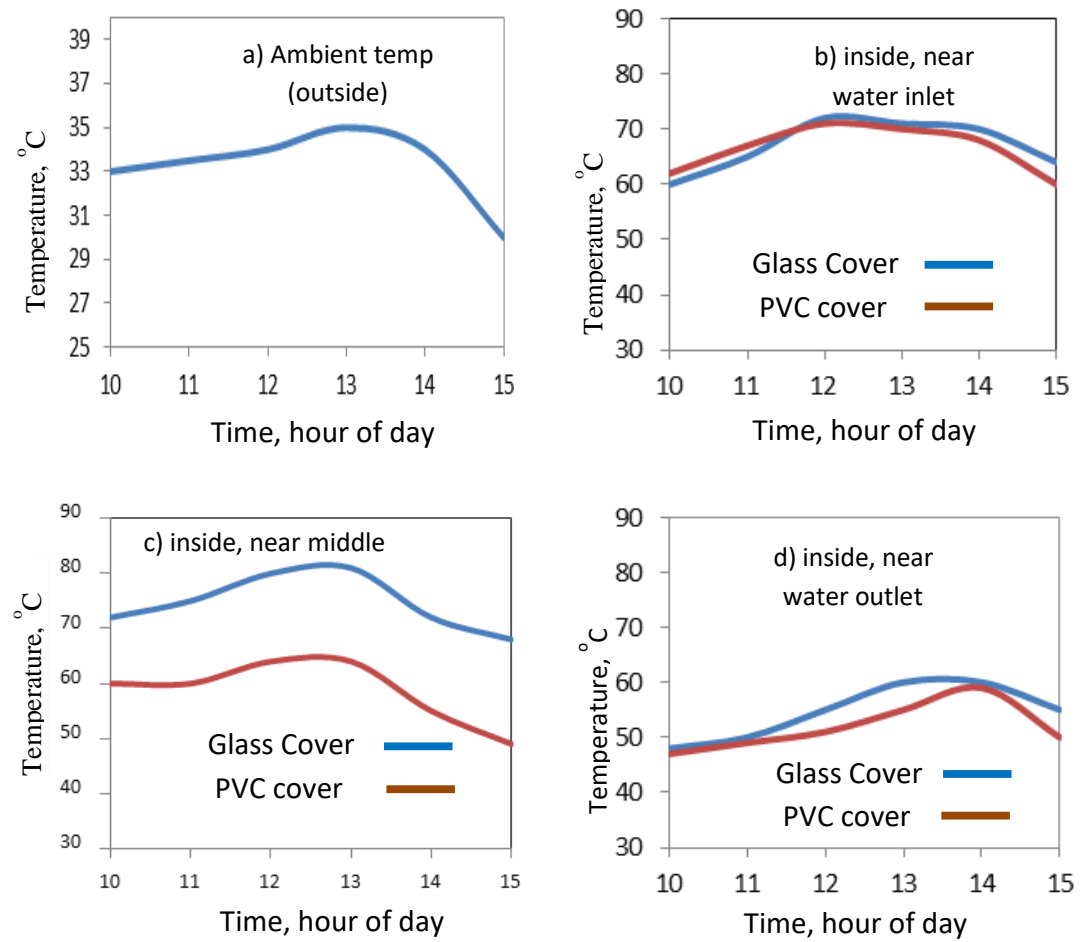

Fig.3: Temperature variation with hours of the day: (a) ambient (outside), (b-d) inside the devices, near water inlet, near middle, near water outlet respectively.

inside the stills, and will be useful in interpreting the results. These plots show that at the middle position of the chambers the temperature is greater by about $10^{\circ} \mathrm{C}$ in the glass covered device compared to that in the PVC sheet covered one. However, near the inlet and outlet, the temperatures are not much different for the two devices. Again, the patterns of temperature variation at the middle of the device with time almost 
follows that of the ambient temperature, but near the water inlet and outlet, the behaviours are slightly different.

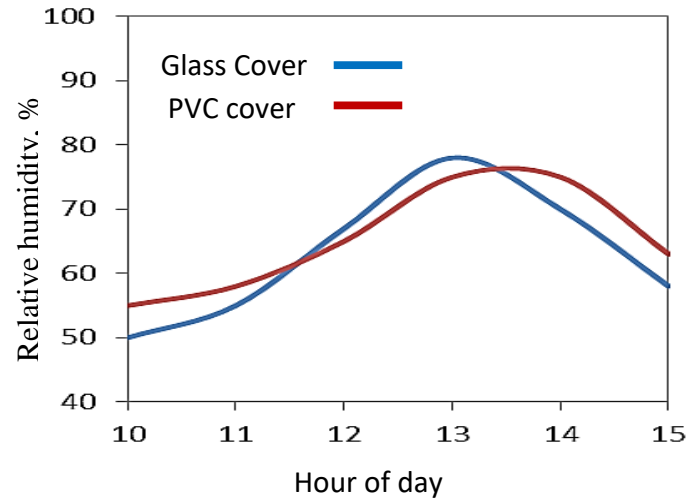

Fig 4: Humidity profile inside the solar stills
The relative humidity distribution inside the chamber is shown in Figure 4. It may be observed that for about 3 hours in the early period and in the late period the relative humidity inside the PVC sheet covered device is higher than that of glass covered device while for about 2 hours in between, it is the reverse. However, the differences are not very high, varying by about $5 \%$. The change in relative humidity also follows the ambient temperature closely.

The amount of distillate collected from the two solar stills on three days in March are given in Table-1. The maximum ambient temperature of the respective days are also indicated.

Table 1: Amount of distillate from two types of solar stills for cover tilt angle of $13^{0}$

\begin{tabular}{|c|c|c|c|c|}
\hline \multirow{2}{*}{$\begin{array}{l}\text { Number of } \\
\text { Experiment }\end{array}$} & \multirow[t]{2}{*}{ Date } & \multirow{2}{*}{$\begin{array}{c}\text { maximum } \\
\text { ambient } \\
\text { temperature, } \\
{ }^{0} \mathrm{C}\end{array}$} & \multicolumn{2}{|c|}{ Distillate volume, $\mathrm{ml}$} \\
\hline & & & PVC sheet cover & Glass cover \\
\hline 1 & 03.03 .2015 & 33.6 & 440 & 1170 \\
\hline 2 & 06.03 .2015 & 35 & 500 & 1150 \\
\hline 3 & 07.03 .2015 & 36 & 538 & 1200 \\
\hline \multicolumn{3}{|c|}{ Average distillate per day } & 493 & 1173 \\
\hline \multicolumn{3}{|c|}{ Average distillate per day for $1 \mathrm{~m}^{2}$ area } & 986 & 2346 \\
\hline
\end{tabular}

From the above table, it is observed that, the amount of distillate produced from the glass covered solar still is more than twice the amount produced by the transparent PVC sheet covered still.

\section{Discussions}

Water obtained through a distillation process is free from pathogens and constitutes a viable source of safe drinking water which also eliminates heavy metals, salts etc. Solar distillation could provide a practical solution to the drinking water needs of the people living in the coastal areas of Bangladesh and other low resource countries where nothing but brackish or saline water is available during most of the year. Again, a domestic scale solar distillation device would be preferred since in isolated villages community based systems providing piped water to individual houses are not practical.

Traditionally, solar distillation devices are made using glass cover. However, in this work, transparent PVC sheet was tried as an alternative since it is cheap, lightweight and not brittle. Again, the model designed uses low cost and easily available materials. This could be an attractive alternative for the proposed application if the output was adequate. 
However, the results show that the output of the device with the PVC sheet cover is less than half (about $42 \%$ ) of that of the device with glass cover, all other parameters remaining nearly the same. This indicates that unless the output of the PVC covered device can be increased significantly, it cannot be recommended for practical use. In order to attempt this one needs to understand the mechanisms that are involved.

In Figure-1 a great amount of condensed water droplets can be observed in the device with the PVC cover, while these are almost absent in the device with glass cover. This could be the main reason behind the low output of the PVC covered device. The condensed droplets scatter the sunlight back and the total solar energy entering the chamber of the PVC covered device is much reduced for this reason. This also then explains the temperature profiles as shown in Figure-3.

Since the inclinations of both the covers are the same, it is likely that the surface adhesion of water to PVC sheet is much greater than that for glass, which is caused by electromagnetic forces created between molecules of water with the cover material that are in close proximity. Therefore, if any coating material is found that can reduce the surface adhesion of water on PVC sheet, or if any other transparent plastic sheet having less surface adhesion is found, it may be possible to use a plastic cover. Otherwise, traditional glass cover is the best solution so far.

\section{Acknowledgment}

One of the authors (HAB) would like to thank Ministry of Science and Technology, Government of the People's Republic of Bangladesh for offering Bangabandhu Fellowship on Science and ICT for this work. The authors would also like to thank the International Science Programme (ISP) of Uppsala University, Sweden for part financial support.

\section{References}

Bendfeld, J., Broker Ch., Menne K., Ortjohann E., Temme L., Vob J. and Carvallo P.C.M.(1998). Design of a PVpowered reverse osmosis plant for desalination of brackish water. Proceedings of $2^{\text {nd }}$ World Conference and Exhibition on Photovoltaic Solar Energy Conversion, Vienna, Austria, PP. 3075-3077.

Gupta, D. B., Mandraha, T. K., Edla P.J. and Pandya, M. (2013). Thermal Modeling and Efficiency of Solar Water Distillation: A Review. American Journal of Engineering Research (AJER), Volume: 02, Issue: 12, PP: 203 213.

Islam M.M., Uddin S.A., Islam Z. and Hossain M.I. (2013). An experimental study on small scale sea water desalination unit through solar power in Cox's Bazar, Bangladesh. Journal of Bangladesh Agricultural University Vol 11(1), PP 165-170.

Khan A., Mojumder S. K., Kovats S., Vineis P. (2008). Saline contamination of drinking water in Bangladesh. The Lancet, Vol. 371,Issue 9610, page 385, 2 February.

Rahman, M. H., Mamtaz, R., Rahman, M. M. (2001). Solar Desalination: Experience in Bangladesh. Department of Civil Engineering, BUET, ISES Solar World Congress, PP 1061-1064.

Rahman, M. H., Mamtaz R., Ferdausi, S. A. (1997). Pilot Solar Desalination Plants in Bangladesh. Water and Sanitation for all: Partnerships and Innovations, $23^{\text {rd }}$ WEDC Conference, Durban, South Africa, PP 178181.

Sadrul, I, A.K.M. Infield, D.G. (2001). Photovoltaic Technology for Bangladesh. Department of Mechanical Engineering, BUET, Dhaka, Bangladesh. 